\title{
Perineal lipoma in a new born baby: It's management
}

\begin{abstract}
Congenital perineal lipomas are rarely seen in a neonate. Only few cases are reported in the
\end{abstract} literature. We report a newborn with this rare condition managed successfully.

Keywords: perineal mass, lipoma, excision
Volume 6 Issue 6 - 2017

\author{
Rajeev Redkar,' Swathi C, ${ }^{2}$ Prajakta Joshi, ${ }^{3}$ \\ Shirin Joshi ${ }^{4}$ \\ 1,2,4 Department of Paediatric Surgery, Lilavati Hospital and \\ Research Centre, India \\ ${ }^{3}$ Department of Pediatrics, Holy Family Hospital, India
}

Correspondence: Rajeev Redkar, Department of Paediatric Surgery, Lilavati Hospital and Research Centre,A-79I, Bandra Reclamation, Bandra West, Mumbai,

Email rajeev.redkar@gmail.com

\section{Introduction}

Congenital perineal lipomas are very rare with only 18 cases reported in the literature. These lesions were more commonly associated with Ano-rectal malformation. Ante-natally these lesions may lead to misdiagnosis of ambiguous genitalia.

\section{Case details}

A new born female baby was delivered to a primigravida at 38 weeks of gestation by normal vaginal route. The mother was registered during her pregnancy and ante-natal scans were done. No ante-natal scan showed renal anomalies or ambiguous genitalia. The period was uneventful. The APGAR score was10/10 at one and five minutes. The birth weight was $3.3 \mathrm{~kg}$. After delivery the baby was examined by a pediatrician. On examination there was a solitary oval shaped swelling of size $5 \times 3 \mathrm{~cm}$ located at the perineal region. The swelling was on the right side of the anal opening. The skin was normal over the swelling. There was no discharge or redness (Figure 1). On palpation there was no local rise of temperature and tenderness. The swelling had a stalk and was soft in consistency. Labial minora, labia majora, urethral, vaginal and anal opening was normal. There was no difficulty in passing urine and stools. The baby was sent to our institution for further management. The ultrasonography of the local swelling was done which showed swelling of size $3.5 \times 3 \times 2.2 \mathrm{~cm}$ with heterogeneous mass and vascular pedicle. The ultrasonography of urinary tract was normal. The baby was planned for excision of the swelling. The mass was removed in Toto. Post operatively there were no complications (Figure 2). The mass was sent for histopathology. Histopathology report showed mature adipose tissue, interspersed with collagen bands and leading to diagnosis of fibro-lipoma.

\section{Discussion}

Congenital perineal lipomas are rare; with 18 other cases. ${ }^{1-7}$ reported in the literature. Isolated congenital perineal lipomas are rare lesions that can lead to misdiagnosis of an accessory scrotum in men, in particular because these two conditions can be associated in over $80 \%$ of cases. ${ }^{8,9}$ These lesions are typically lobulated, round or pedunculated subcutaneous masses. They are usually smooth, soft, mobile, and non-tender. Perineal lipoma may arise from the mid-perineum but are most commonly lateral in location. The differential diagnosis includes lipoblastoma, which is a benign condition distinguishable from lipoma only histologically. Infantile hemangiomas, hamartomas, and choristoma may grossly appear similar to a lipoma. Moreover, these lesions may be associated with external genital and anorectal malformations. Such anomalies include an accessory scrotum or labioscrotal fold, anal atresia, a rectoperineal or rectovestibular fistula, and a persistent cloaca., ${ }^{2,7}$ Finally, ambiguous genitalia must be entertained, particularly as an accessory scrotum or labioscrotal fold may be present..$^{1,2,5-7}$ However, a phallus will be located in the midline, whereas most lipomas generally arise laterally.

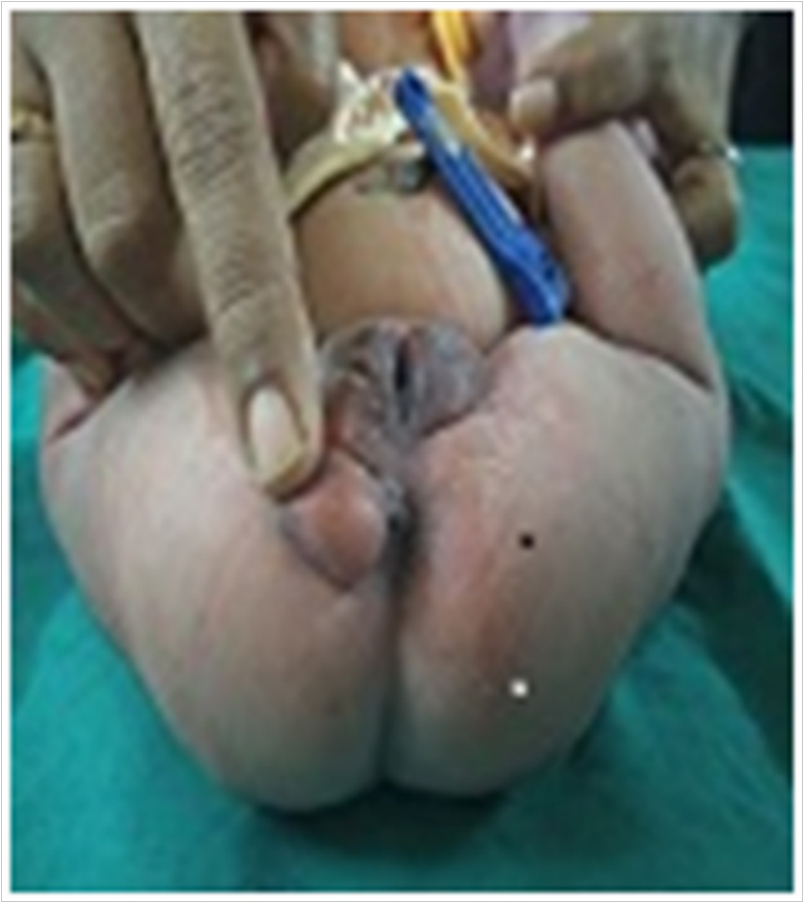

Figure I Pre-operative.

Evaluation before delivery with ultrasonography and after birth by physical examination is helpful for diagnosis. Magnetic resonance imaging can assess associated anomalies, evaluate the blood supply, and define the extent of invasion which assists in pre-operative surgical planning. A complete evaluation of the uro-genital and anorectal tract is recommended taking into account related anomalies described such as renal agenesis, anorectal malformations, scrotum and penile anomalies. ${ }^{8-10}$ The treatment of a presumed lipoma is local excision with no anticipated recurrence. 


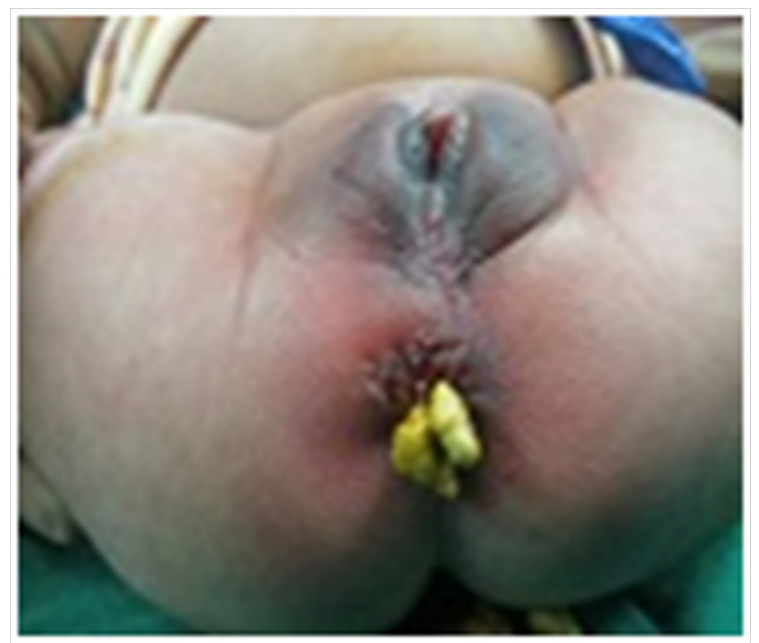

Figure 2 Post-operative with scar and stool at anal verge.

\section{Conclusions}

Congenital perineal lipomas can be diagnosed at an early stage in a newborn which can be managed by surgical excision.

\section{Acknowledgments}

None.

\section{Conflicts of interest}

The authors declare no conflicts of interest.

\section{References}

1. Chanda MN, Jamieson MA, Peonaru D. Congenital perineal lipoma presenting as "ambiguous genitalia":a case report. J Pediatr Adolesc Gynecol. 2000;13(2):71-74.

2. Redman JF, Ick KA, North PE. Perineal lipoma and an accessory labial fold in a female neonate. J Urol. 2001;166(4):1450.

3. Ogasawara Y, Ichimiya M, Nomura S, et al. Perineal lipoma in a neonate. J Dermatol. 2001;28(3):165-167.

4. Shaul DB, Monforte HL, Levitt MA, et al. Perineal lipoma in a neonate. J Dermatol. 2001;28:165-167.

5. Guerra-Junior G, Aun AME, Miranda ML, et al. Congenital perineal lipoma presenting as ambiguous genitalia. Eur $J$ Pediatr Surg. 2008;18(4):269-271.

6. Soccorso G, Ninan GK. A case of perineal lipoma with accessory scrotum and pseudodiphallia. Eur J Pediatr Surg. 2001;9:55-56.

7. Chu SM, Ming YC, Chao HC, et al. An accessory labioscrotal fold associated with anorectal malformation in female neonates. $J$ Pediatr Surg. 2009;44(4):17-19.

8. Park KH, Hong JH. Perineal lipoma in association with scrotal anomalies in children. BJU Int. 2006;98(2):409-12.

9. Wax JR, Pinette MG, Mallory B, et al. Prenatal sonographic diagnosis of a perineal lipoma. J Ultrasound Med. 2010;29:1257-1259.

10. Wester T, Rintala R. Perineal lipomas associated with anorectal malformations. Pediatr Surg Int. 2006;22(12):979-981. 